\title{
Detailed Aerosol Optical Depth Intercomparison between Brewer and Li-Cor 1800 Spectroradiometers and a Cimel Sun Photometer
}

\author{
V. E. Cachorro, A. Berjón, C. Toledano, S. Mogo, ${ }^{*}$ N. Prats, and A. M. de Frutos \\ Grupo de Óptica-Atmosférica, Universidad de Valladolid, Valladolid, Spain
}

J. M. Vilaplana, M. Sorribas, And B. A. De La Morena

ESAT-El Arenosillo, INTA/División de Ciencias del Espacio, Huelva, Spain

J. GRÖBNER

Physikalisch-Meteorologisches Observatorium Davos, World Radiation Center, Davos, Switzerland

\author{
N. LAULAINEN
}

Pacific Northwest National Laboratory, Richland, Washington

(Manuscript received 5 September 2008, in final form 26 January 2009)

\begin{abstract}
Aerosol optical depth (AOD) using different instruments during three short and intensive campaigns carried out from 1999 to 2001 at El Arenosillo in Huelva, Spain, are presented and compared. The specific aim of this study is to determine the level of agreement between three different instruments running in operational conditions. This activity, however, is part of a broader objective to recover an extended data series of AOD in the UV range obtained from a Brewer spectroradiometer. This instrument may be used to obtain AOD at the same five UV wavelengths used during normal operation for ozone content determination. As part of the validation of the Brewer AOD data, a Cimel sun photometer and another spectroradiometer, a Li-Cor 1800, were used. A detailed comparison of these three instruments is carried out by means of near-simultaneous measurements, with particular emphasis on examining diurnal AOD variability. Absolute AOD uncertainties range from 0.02 for the Cimel to 0.08 for the Brewer, with intermediate values for the Li-Cor 1800. All data during the comparison are in reasonable agreement, when taking into account the different performance characteristics of each instrument. The comparison also demonstrates current deficiencies in the Brewer data and thus the difficulty to determine AOD values with low errors.
\end{abstract}

\section{Introduction}

Monitoring one of the most basic aerosol parameters, the aerosol optical depth (AOD), is a main experimental task in aerosol studies, used to quantify the amount and variability of aerosol loading in the atmospheric column over a certain area. The emergence of the Aerosol

\footnotetext{
* Current affiliation: Departamento de Física, Universidad de Beira Interior, Covilhã, Portugal.
}

Corresponding author address: Victoria E. Cachorro Revilla, Grupo de Óptica-Atmosférica GOA-UVA, Universidad de Valladolid, Valladolid, Spain, ES-47071.

E-mail: chiqui@goa.uva.es
Robotic Network (AERONET)-PHOTONS network (Holben et al. 1998, 2001; more information available online at http://aeronet.gsfc.nasa.gov and http://wwwloa.univ-lille1.fr/photons/) and the World Meteorological Organization-Global Atmosphere Watch (WMOGAW; Wehrli 2000), with their expansion over the past years, together with more frequent and increasingly reliable retrieval of aerosol parameters by satellite instruments (Chu et al. 2002; Masuda et al. 2002; Ichoku et al. 2005) has changed the perspective of aerosol studies. At present, most validations of satellite aerosol products use AERONET data by means of relatively simple correlations.

The AOD data in the UV are necessary for multiple applications, but they are scarce and their quality is 
difficult to assess. Although AERONET provides AOD data at UV wavelengths ( 340 and $380 \mathrm{~nm}$ ) at a number of stations, these data are scarce compared to those in the visible and near-infrared. Precision filter radiometers (PRFs)-GAW instruments, located only in few remote sites, measure AOD at $368 \mathrm{~nm}$. The extensive UV Brewer network, designed to provide worldwide ozone column data, also has the potential of providing AOD at UV wavelengths. Retrieval of AOD data is a relatively new activity within the Brewer user community, but one that is of great interest because of the network's global nature and the long datasets available at many sites. Although various papers are published about such retrievals (Carvalho and Henriques 2000; Gröbner et al. 2001; Cachorro et al. 2003; Cheymol and Backer 2003; Gröbner and Meleti 2004; Kazadzis et al. 2005; Cheymol et al. 2006), there are two main drawbacks in this retrieval. First, it is based on spectroradiometer measurements, which are always more complicated (use of attenuation filters, low time resolution, etc.) than current filter radiometers. Second, it is usually based on "on-site" Langley calibration, as is well described by Cheymol et al. (2006). This type of calibration presents strong difficulties at many sites because of high AOD variability and cloud occurrence. Thus, the retrieval of AOD from Brewer measurements needs a careful assessment at each site.

With the limitations described above, our objective is to evaluate the accuracy and consistency of the Brewer AOD retrievals at El Arenosillo. This AOD data series (1997-present) will be investigated based on a comparison with other operational instruments present at this site, a Li-Cor 1800 spectroradiometer and a Cimel 318-2 sun photometer. In this investigation about the UV spectral range, the AERONET AOD data in the visible and infrared are used as a well-established reference for AOD behavior in the atmosphere. The Li-Cor provides the AOD spectrum (300-1100 nm) and therefore is used to provide the link between AOD in the UV (obtained with the Brewer) and the visible spectral range (from the Cimel). Note that the Cimel at El Arenosillo has no UV channels in the analyzed periods.

The AOD database at El Arenosillo started with measurements obtained with the Li-Cor 1800 spectroradiometer from 1996 to 1999 (Vergaz et al. 2005), and continued with the measurements of the AERONET Cimel sun photometer since 2000 (Toledano et al. 2007). To attain our objective we carried out a comparison of Brewer data with those from the latter two instruments during common measurement periods. The Brewer-Li-Cor and the Brewer-Cimel pairs have long periods of concurrent observations, but only during short intensive campaigns were all three instruments available. The Li-Cor was operated during these inter- comparison campaigns specifically to assess the continuity of the AOD data series.

The retrieval-assessment of Brewer AOD data is planned to be carried out in two steps. First, a detailed comparison is performed using near-instantaneous data measured during short and intensive campaigns (as presented in this article). Second, we will perform a comparison of near-instantaneous (when possible) daily and monthly averages data during long time periods, from 1997 to the present (work in progress). Specifically, the work presented here attempts to establish a realistic and reliable evaluation of AOD data between both spectroradiometers and the Cimel sun photometer based on data from three short and intensive campaigns. As a result of the different characteristics of the three instruments, the intercomparison does not satisfy all the requirements for an accurate calibration, but it is sufficient to establish the level of agreement for the instruments operating in their normal mode. In turn, this may serve as insight for recovery of a reliable Brewer AOD data series as in Kazadzis et al. (2007). To use only daily or monthly average data for comparison is not sufficient to know the AOD agreement.

The paper is structured as follows: section 2 describes the measurement site and main instrument characteristics. Section 3 gives the basic methodology, with special emphasis on uncertainty evaluation. Section 4 provides a discussion of the main features of the diurnal AOD comparison.

\section{ESAT-EI Arenosillo station and instrument characteristics}

The Atmospheric Sounding Station (Esat-El Arenosillo; $37.1^{\circ} \mathrm{N}, 6.7^{\circ} \mathrm{E}, 0 \mathrm{~m}$ ASL) belongs to the Spanish National Institute of Aerospace Technology (INTA), and is located in southwestern Spain (Huelva region), in the Atlantic coastal area of the Cadiz Gulf. This station is located close to the Parque Nacional de Doñana, one of the largest and unique natural reservoir areas in Europe, with Mediterranean forest and moving dunes. Local industrial pollutants are injected into the atmosphere some 15-30 km away from the station by the industrial belt of Palos-Huelva. Evidence seems to indicate that the loading may not be relevant for columnar aerosol measurements. This station also is part of the WMO ozone network (number 213), and is equipped with a Dobson instrument and a Brewer spectrometer, the latter in operation since 1997. This instrument also provides routine global spectral UV irradiances. The climate of this area may be considered as maritime Mediterranean, with more than $60 \%$ clear, sunny days during the year. AERONET statistics show that only about $5 \%$ of days per year there are no Cimel AOD measurements. Thus, 
TABLE 1. Summary of instrument characteristics for direct sun measurements; C-H is the calibration method described by Carvalho and Henriques (2000) and G is the method by Gröbner et al. (2001).

\begin{tabular}{llcccc}
\hline \hline \multicolumn{1}{c}{ Instrument } & \multicolumn{1}{c}{ Model } & Wavelengths (nm) & FWHM (nm) & Sampling & Calibration \\
\hline Brewer (No. 150) & Mk-III & $306.6,310.1,313.5,316.8,320.1$ & 0.62 & - & $\begin{array}{c}\text { On site Langley (C-H method) or } \\
\text { intercomparison (G method) } \\
\text { Li-Cor }\end{array}$ \\
Li-1800 & 300 to 1100 & 6.2 & $1 \mathrm{~nm}$ & $\begin{array}{c}\text { Laboratory (lamp) } \\
\text { Intercomparison with master }\end{array}$ \\
\hline
\end{tabular}

this station is a convenient site for solar radiation measurements and radiometric aerosol studies.

Only a short description of the three instruments used for AOD determination is given here, because detailed information can be found in various works (Holben et al. 1998; Cachorro et al. 2000; Marenco et al. 2002; Kerr 2002; Martinez-Lozano et al. 2003; Vergaz et al. 2005; Estelles et al. 2006; Kerr and Davis 2007). A summary is provided in Table 1. The commercial Li-Cor 1800 spectroradiometer has been used for long-term aerosol studies at different sites of Spain, such as Valladolid area (Cachorro et al. 2000) and the Esat-El Arenosillo station (Vergaz et al. 2005). Spectroradiometer systems with moderate resolution, such as the Li-Cor 1800, are frequently used for AOD retrieval during short periods as can be seen in various papers (Ahern et al. 1991; Cuomo et al. 1993; Esposito et al. 1996; Carlund et al. 2003), but not generally for long-term aerosol monitoring because of difficulties and intricate tasks related to the calibration, maintenance, and operation compared to that required for filter radiometers like the Cimel.

The Li-Cor spectroradiometer (Table 1) covers the spectral range 300-1100 $\mathrm{nm}$ with variable wavelength resolution. We currently use $1-\mathrm{nm}$ sampling for the spectral measurements. One measurement (full spectrum) typically takes $40 \mathrm{~s}$. The instrument function has been determined in our optics laboratory to have a full width at half maximum (FWHM) of $6.2 \pm 0.3 \mathrm{~nm}$. For measuring the direct component of solar radiation, a collimator system with an instantaneous field of view (IFOV) of $2.3^{\circ}$ was designed and constructed by Grupo de Óptica-Atmosphérica-Universidad de Vallodolid (GOAUVA) and coupled to the original Teflon cosine receptor with an IFOV of $2 \pi$ sr designed for global irradiance measurements. Light is collected by the cosine receiver and guided into the spectroradiometer by means of an optical fiber. More details about the Li-Cor spectroradiometer characteristics and measurements, calibration, errors, maintenance, and comparisons can be found in the literature (Li-Cor 1989; Martinez-Lozano et al. 2003; Vergaz et al. 2005; Estelles et al. 2006).

For short campaigns, the Li-Cor spectroradiometer is calibrated before and after the campaign in order to minimize the measurement error caused by calibration. A Li-Cor 1800-02 Optical Radiation Calibrator was used for this purpose. We have observed that the Li-Cor spectroradiometer shows high stability from 400 to $950 \mathrm{~nm}$, with the differences between successive calibrations being partly caused by the uncertainties and variability of the used irradiance calibration sources (see Vergaz et al. 2005). Therefore, considering a laboratory calibration uncertainty of $3 \%$ to $4 \%$ for the Li-Cor and previous intercomparison results between Li-Cor instruments (Martinez-Lozano et al. 2003; Redondas et al. 2004; Estelles et al. 2006), we define an upper limit for the relative uncertainty for the measured direct irradiance of $5 \%$ from 360 to $1000 \mathrm{~nm}$.

The observed variability in the UV range between successive calibrations (Vergaz et al. 2005) is also caused by calibration source uncertainties but mainly by the low sensitivity of the Li-Cor instrument in this spectral range, oscillating between $10 \%-20 \%$, although an estimation of $7 \%-10 \%$ at $320-360-\mathrm{nm}$ range is very realistic. Despite this rather large uncertainty, we have obtained successful comparative results (Gröbner et al. 2001) in the UV range under specific and well-controlled conditions, like short campaigns, such as those described in this paper. The wavelength range $1020-1100 \mathrm{~nm}$ is very sensitive to temperature variations, but under controlled conditions an uncertainty varying from $5 \%$ to $10 \%$ at $1020 \mathrm{~nm}$ is a good estimate for the measured irradiance values. Because of this high measurement uncertainty, the retrieved AOD values have significantly higher uncertainties than the Cimel sun photometer.

A description of the Cimel sun photometer can be found in Holben et al. $(1998,2001)$ and the AERONET Web page (http://aeronet.gsfc.nasa.gov; http://www-loa. univ-lille1.fr/photons/). The Cimel installed at El Arenosillo (Cimel 318-2 polar) provides AOD data over the visible and near-infrared spectrum. During the campaigns the Cimel sun photometer was operated according to the AERONET protocols and measurement schedule. The four nominal wavelengths of the polarized model are 440, 670, 870, and $1020 \mathrm{~nm}$.

Brewer instruments are designed for ozone monitoring (Kerr et al. 1981) using five wavelengths: 306.6, $310.1,313.5,316.8$, and $320.1 \mathrm{~nm}$, although a few differences exist between instruments within the Brewer network (single or double monochromator). A single scan takes $3 \mathrm{~min}$. They are also designed to measure the 
spectral UV global irradiance from 286.5 to $363 \mathrm{~nm}$ (depending on the model, single or double monochromator) with a sampling step of $0.5 \mathrm{~nm}$ and nominal FWHM of $0.62 \mathrm{~nm}$. Our system, MK-III 150, has a double monochromator and operates according to the requirements of the Brewer network. It is calibrated periodically against the Brewer Reference Traveling Standard 17 operated by the International Ozone Services (IOS).

From 1999 to present, three calibration-intercomparison campaigns have been carried out at El Arenosillo by the Spanish Brewer network, dependent on the Spanish Meteorological Institute (INM), to ensure the quality control of calibration, maintenance, and measurements. (Extensive details about the Brewer instrument characteristics, performance, and maintenance may be found at http://www.woudc.org/.) A detailed description of the ability of this instrument to monitor ozone and other atmospheric variables may be found in Kerr (2002) and Kerr and Davis (2007).

Uncertainties associated with Brewer measurements are difficult to evaluate (Kerr 2002; Kerr and Davis 2007; Gröbner and Meleti 2004; Arola and Koskela 2004; Kazadzis et al. 2005), because ozone, AOD, and global UV irradiance follow different calibration procedures and retrieval methods. Note that the Brewer was primarily designed for ozone content retrieval and not for AOD; therefore, various methods have been developed for this determination, namely, how to get the direct irradiance to apply Beer's law (for details, see Kazadzis et al. 2005).

The results that we will show in section 4 belong to three different campaigns. For the Li-Cor direct sun measurements we used a sun-tracking system, although a manual supervision was carried out to guarantee that the spectrum is measured either with or without clouds during these short intensive campaigns. Note that for an intercomparison (not for calibration) the change of the atmospheric conditions may be seen as a positive effect in order to see how the instruments track atmospheric changes. Concurrently, the Cimel and Brewer instruments make their systematic routine measurements programmed according to their respective network protocols. Thus, no other special schedules were followed for these campaigns. Only the Li-Cor followed a separate operation protocol, which was synchronized as closely as possible to the Cimel sun photometer.

\section{Methodology: Retrieval and uncertainties of the aerosol optical depth}

\section{a. Aerosol optical depth retrieval}

We describe briefly the general procedure used to determine the experimental AOD. The total spectral optical depth of the atmosphere $\tau(\lambda)$ is obtained from the absolute direct solar irradiance measured at ground level, $F(\lambda)$, using the Beer-Lambert law

$$
F(\lambda)=F_{o}(\lambda) \exp [-\tau(\lambda) m],
$$

where $F_{o}(\lambda)$ is the irradiance at the top of the atmosphere corrected for the sun-earth distance. This spectrum was taken from Gueymard (2004) for Li-Cor evaluation. The air mass $m$ is given by the formula by Kasten and Young (1989). In the case of the Cimel sun photometer $F_{o}$ is the extraterrestrial signal (the calibration constant) and $F$ is the measured signal of the instrument. For the Brewer, the procedure to determine the AOD is basically the same once we have the absolute direct irradiance data, but as explained in the earlier references, different procedures may be considered to get the direct irradiance data $F$ and the calibration constants $F_{o}$.

The aerosol optical depth $\tau_{a}$ at a given wavelength $\lambda$ is given by

$$
\tau_{a}(\lambda)=\tau(\lambda)-\tau_{R}(\lambda) P / P_{0}-\tau_{g}(\lambda),
$$

where $\tau_{R}(\lambda) P / P_{0}$ is the contribution caused by Rayleigh scattering, corrected by local pressure $\left(P\right.$ and $P_{0}$ are the pressure at site and sea level, respectively) and $\tau_{g}(\lambda)$ is the absorption by atmospheric gases in the affected wavelengths $\left(\mathrm{O}_{3}, \mathrm{NO}_{x}, \mathrm{SO}_{x}\right.$, etc. $)$. In our case we are interested in the comparison at selected wavelengths with small absorption although ozone absorption needs to be considered. Cimel data are corrected using ozone monthly climatology, although in this case reliable data of ozone content given by Brewer instruments were used.

\section{b. Uncertainties in the AOD retrieval}

A brief analysis about the uncertainties of the retrieved AOD is now required. According to Eq. (2), the uncertainty of the AOD is given by the uncertainties in the total optical depth, Rayleigh, and gas absorption optical depth. The Rayleigh uncertainty can be neglected with respect to the uncertainty of the total optical depth, and the same is considered for the uncertainty associated with ozone absorption at the nominal wavelengths of 320 and $670 \mathrm{~nm}$. Therefore, for the total optical depth and Eq. (1) the main uncertainty is given by the uncertainty of the extraterrestrial irradiance $F_{o}$ (the calibration factor in the case of Cimel) and the measured irradiance $F$. In the case of the Cimel the uncertainty associated with the measured solar radiation is via the uncertainty of calibration because other effects may be neglected if we assume a proper functioning of the instrument.

As demonstrated by various authors (Reagan et al. 1986; Cachorro et al. 2000, 2004), the absolute uncertainty 
of the aerosol optical depth given by the error propagation theory is

$$
\begin{aligned}
\Delta \tau_{a}= & \frac{1}{m}\left[\tau_{a} \Delta m+\varepsilon\left(F_{o}\right)+\varepsilon(F)\right]+P / P_{0} \Delta \tau_{R} \\
& +\Delta P / P_{0} \tau_{R}+\Delta \tau_{g}
\end{aligned}
$$

where $\Delta$ and $\varepsilon$ represent absolute and relative uncertainties, respectively. Note from Eq. (3) that the absolute uncertainty depends on $m$ and therefore is not constant. It has a maximum uncertainty at solar noon $(m \approx 1)$ and a minimum at sunrise and sunset, thus producing a diurnal variation. Since the relative uncertainty depends on the absolute AOD value, this gives rise to a wide range of relative uncertainties. For instance, a $1 \%(5 \%)$ uncertainty in the measured irradiance, neglecting the contribution of other uncertainty terms in Eq. (3), gives rise to $\Delta \tau_{a}=0.01(0.05)$ for $m=1$, which represents a $10 \%(50 \%)$ relative uncertainty for a typical AOD of 0.1 .

For the Li-Cor the uncertainty of $5 \%$ for the measured visible-near-infrared spectral irradiance $F(\lambda)$, which contains the error of the calibration procedure as discussed above, is the most relevant uncertainty, because the uncertainties in the air mass $\Delta m$ may be neglected for solar zenith angles (SZA) less than $60^{\circ}$. According to Gueymard (2004), we can assign an uncertainty of $1.7 \%$ for the extraterrestrial irradiance. Thus, from Eq. (3) we have the absolute uncertainty of the AOD ranging from \pm 0.02 to \pm 0.05 within an airmass range from 1 to 3 . Then we should add the uncertainty caused by Rayleigh optical depth and gaseous absorptions. The uncertainty in the UV for Li-Cor AOD retrieval may reach values as high as 0.08 , or more than $100 \%$ for the relative uncertainty.

For Cimel photometers, AERONET assumes an absolute uncertainty of $0.01-0.02$ for field measurements (larger for shorter wavelengths), based on the uncertainties in the intercalibration process with a reference instrument (Holben et al. 1998). Furthermore, following AERONET protocols, an interpolation of the calibration coefficients obtained before and after the measurement period is carried out, in order to minimize the effect of filter degradation. Then data can reach level 2 (quality assured).

For Brewer AOD retrieval the uncertainty is higher than that given for the Cimel sun photometer and less than the Li-Cor uncertainty in the UV range. Apart from the fact that calibrations at UV wavelengths have a higher associated uncertainty, additional elements need to be considered. For example, a sophisticated filter attenuation system (see Marenco et al. 2002) considerably complicates the number of calibration constants (up to 30) for the Brewer. Arola and Koskela (2004) made a detailed evaluation of the uncertainty of the Brewer AOD trying to justify the relatively large number of negative Ångström exponent $(\alpha)$ values given in various references (Kirchhoff et al. 2001; Jaroslawsky et al. 2003; Cheymol and Backer 2003), which are indicative of incorrect calibration factors. The ozone absorption and the proximity of the Brewer wavelength channels make the Angström exponent determination very uncertain.

Cheymol and Backer (2003) evaluate the error of AOD determination caused by the uncertainty of the ozone amount determination (or ozone absorption), giving absolute error values (see their Table 3), but other effects must be take into account to estimate the total relative error for AOD Brewer determination. Arola and Koskela (2004) estimated a total uncertainty of 0.08 extracted from AOD differences between 306.1 and $320.1 \mathrm{~nm}$ caused by different effects but without analyzing an estimated uncertainty caused by the intrinsic problem of the absolute calibration (Langley, laboratory, or other procedure). A similar estimated value is given in Kazadzis et al. (2005). Although the given uncertainty is rather large, our experience in the retrieval of Brewer AOD (Cachorro et al. 2003) indicates an even less optimistic estimation under operational conditions, which is well assessed by the published negative Angström exponent data already mentioned. However, when daily mean AOD values are determined, the unrealistic observed diurnal variations are not seen because they partially compensate, resulting in apparently reliable mean values. In our case, we directly compare quasi-simultaneous AOD values, taking into account the different measurement times of each instrument and other characteristics, such as spectral resolution in the case of the Brewer and the $\mathrm{Li}$-Cor.

Furthermore, we emphasize that if an incorrect calibration is used, this erroneous value will be reflected in the measured AOD value producing systematic diurnal cycles, as we have demonstrated by means of the KCICLO method (Cachorro et al. 2004, 2008).

The above discussion clearly shows the real difficulties in determining AOD with low uncertainty for all these systems. We also observe that neither the Li-Cor nor the Brewer spectroradiometer satisfy the recommendation of the WMO/GAW (WMO/GAW 2003) of 0.02 for the acceptable estimated uncertainty. Only the Cimel fulfils the recommendation. The difficulty to get AOD values with low uncertainty is discussed in the next section by means of the obtained results.

\section{Results and discussion}

The extended discussion above about the uncertainties associated with AOD determination was deemed 

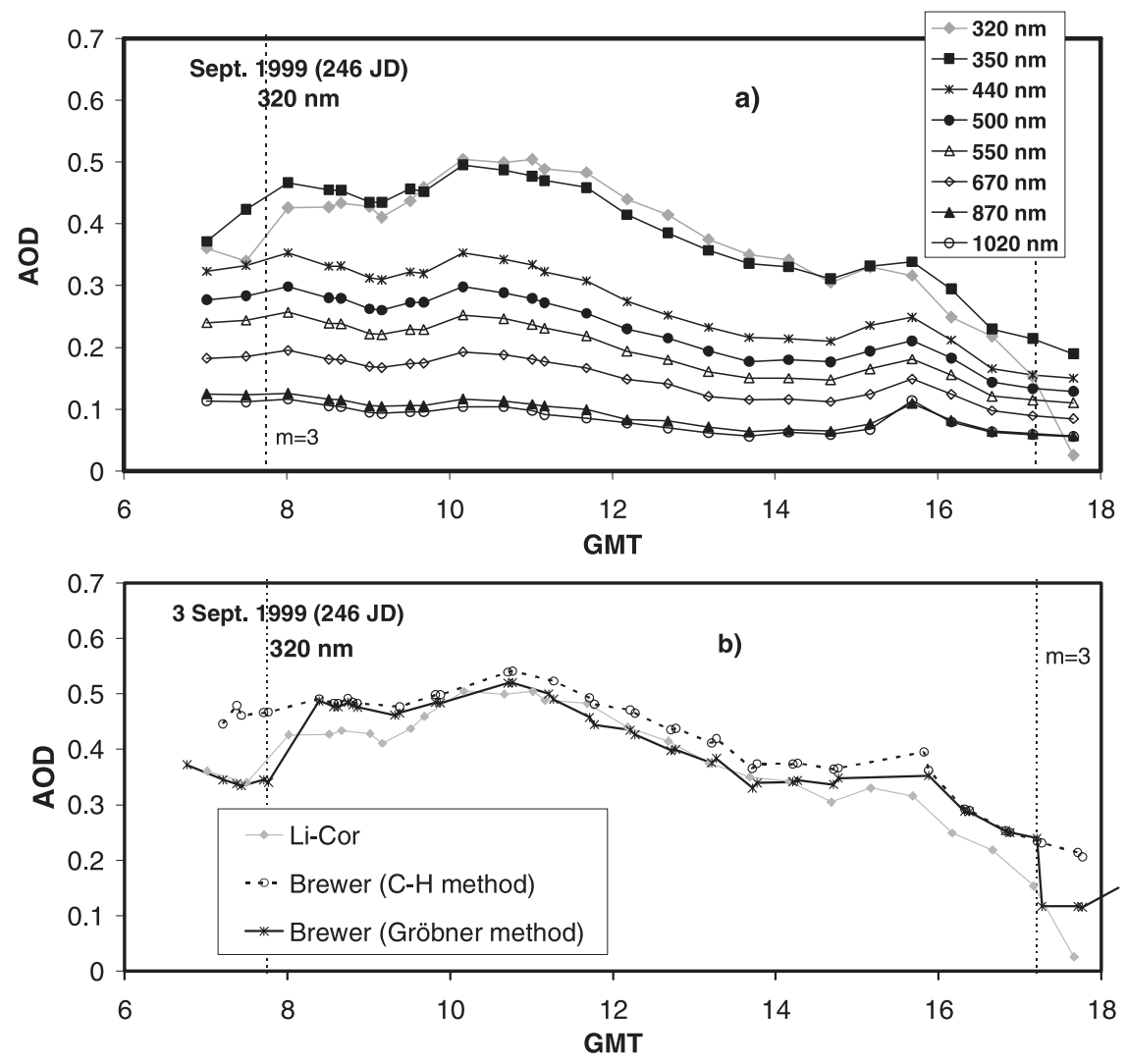

FIG. 1. (a) AOD time series obtained with the Li-Cor at various wavelengths on 3 Sep 1999. (b) Comparison of the AOD time series on 3 Sep 1999 given by the Brewer 150 (using two methods) and Li-Cor. Vertical dotted lines indicate air mass 3 in the morning and evening (approximate $\mathrm{SZA}=70^{\circ}$ ).

necessary, because our results show a large range of differences, even with careful and detailed temporal comparisons. This work is not focused on calibration, we emphasize that it is an intercomparison process to evaluate as precisely as possible any systematic differences in AOD values arising from the different instruments working in operational conditions. Furthermore, we have made realistic error estimations, which often results in uncertainties that are larger than those published in the literature.

\section{a. First campaign: September 1999}

The results presented here correspond to those obtained from 1 to 10 September 1999, during the First Iberian UV-Visible (VIS) Instrument Intercomparison (Martinez-Lozano et al. 2003; Labajo et al. 2004), carried out at El Arenosillo. In this campaign, focused on irradiance comparisons, a large number of spectroradiometers was available. The Brewer and the Li-Cor were calibrated during the campaign for global irradiance measurements. New calibration values for direct irradiance were also obtained for the Li-Cor.
We select several wavelengths from the Li-Cor AOD spectra for comparison with the Brewer at $320 \mathrm{~nm}$ and with the Cimel at 440, 670, 870, and $1020 \mathrm{~nm}$. We show for illustration in Fig. 1a the AOD time series obtained with the Li-Cor spectroradiometer at various selected wavelengths from 320 to $1020 \mathrm{~nm}$ on 3 September 1999. The AOD values at these wavelengths are very high; for 320 and $350 \mathrm{~nm}$, AOD varies from about 0.4 to 0.5 during the morning and decreases to 0.3 in the afternoon. Note the pronounced curvature at these two wavelengths compared to the $440-\mathrm{nm}$ wavelength and the more erratic behavior of $320 \mathrm{~nm}$ compared to $350 \mathrm{~nm}$. Although in this case the curvature is not so pronounced, it is a general feature caused by the higher calibration error in the UV wavelengths. The AOD (440 nm) follows a similar temporal evolution with also relatively high values, from 0.3 to 0.2 ; similar behavior occurs for the other wavelengths. The corresponding Ångström exponent, about 1.2 in the visible range (Labajo et al. 2004), suggests a mixed aerosol type.

Two different methods for AOD retrieval were applied to the Brewer data, each based on the respective 
TABLE 2. Mean absolute and relative differences of the AOD values at $320 \mathrm{~nm}$ with the corresponding standard deviations given by the comparison between the Li-Cor and Brewer (two methods) and between the two Brewer methods using all the data of the campaign of September 1999.*

\begin{tabular}{lccc}
\hline \hline \multicolumn{1}{c}{ AOD comparison 1999} & Lic-Brew $(\mathrm{C}-\mathrm{H})$ & Lic-Brew $(\mathrm{G})$ & Brew $(\mathrm{C}-\mathrm{H})-\mathrm{Brew}(\mathrm{G})$ \\
\hline Mean absolute difference & -0.042 & -0.035 & -0.007 \\
STD & 0.031 & 0.028 & 0.033 \\
Mean relative differences (\%) & -14.2 & -10.9 & -4.01 \\
STD $(\%)$ & 17.7 & 8.8 & 10.7 \\
\hline
\end{tabular}

* $\mathrm{MAD}=\frac{1}{N} \sum_{i=1}^{N} \mid \mathrm{Li}$-Cor-Brewer $\left.\right|_{i}$. Although absolute values are taken, the negative sign indicates that Brewer always gives greater AOD values than Li-Cor, and so on.

method to obtain the calibration constants: 1) the method by Carvalho and Henriques (2000; C-H in Fig. 1 b and Table 1), using selected days at El Arenosillo to determine on-site the calibration constants at the five ozone wavelengths by the Langley procedure; and 2) the method described in Gröbner et al. (2001; denoted G). In the latter, another Brewer spectroradiometer (number 157), belonging to Izaña Observatory, was used as a master to transfer the calibration to Brewer 150 . The calibration constants of Brewer 157 were obtained from a large number of Langley plots at Izaña Observatory (2367 $\mathrm{m} \mathrm{ASL}$ ). The reason for using these two different methods is to evaluate the resulting differences, because for the Brewer 150 operating according to normal protocols, only the Carvalho and Henriques method can be used. We could also use the calibration constants provided by the IOS, but the first results showed great discrepancies and no reliable retrievals were possible.

The AOD comparison between the Li-Cor and the two methods applied to Brewer 150 at $320 \mathrm{~nm}$ is reported in Table 2. As can be seen, the absolute differences have average values of $-0.042,-0.035$, and -0.007 , and relative differences of $-14.4 \%,-10.9 \%$, and $-4.1 \%$, along with their corresponding standard deviations (STDs), respectively. For illustration, we only show the comparison on 3 September in Fig. 1b. As expected the differences between the two methods were less than the comparison between the Li-Cor and the Brewer, although the $\mathrm{C}-\mathrm{H}$ method shows a slight better agreement with the Li-Cor. Further, if we use the 350and $440-\mathrm{nm}$ Li-Cor channels as a reference, the $\mathrm{C}-\mathrm{H}$ method provides a better behavior in the morning and evening. Note the AOD jumps with the G method at 8 and $17 \mathrm{~h}$. The Brewer-Li-Cor agreement is better at noon, also suggesting a lack of sensitivity of the Li-Cor at large air masses. In Fig. 1, vertical dotted lines indicate the UTC time corresponding to air mass 3 (SZA = $70^{\circ}$ ) in the morning and evening. The airmass upper limit in the UV for Langley calibration is 3 or even less (Slusser et al. 2000).

The Cimel 114 sun photometer was received from the National Aeronautic and Space Administration Goddard Space Flight Center (NASA GSFC) calibration for installation at El Arenosillo in time for the campaign. However, some problems were detected in the robotic system and it only worked properly on 8 September (day 251), allowing a comparison with the Li-Cor only on this day; see Fig. 2. As can be observed, the agreement between the AOD $(440 \mathrm{~nm})$ data is not very good,

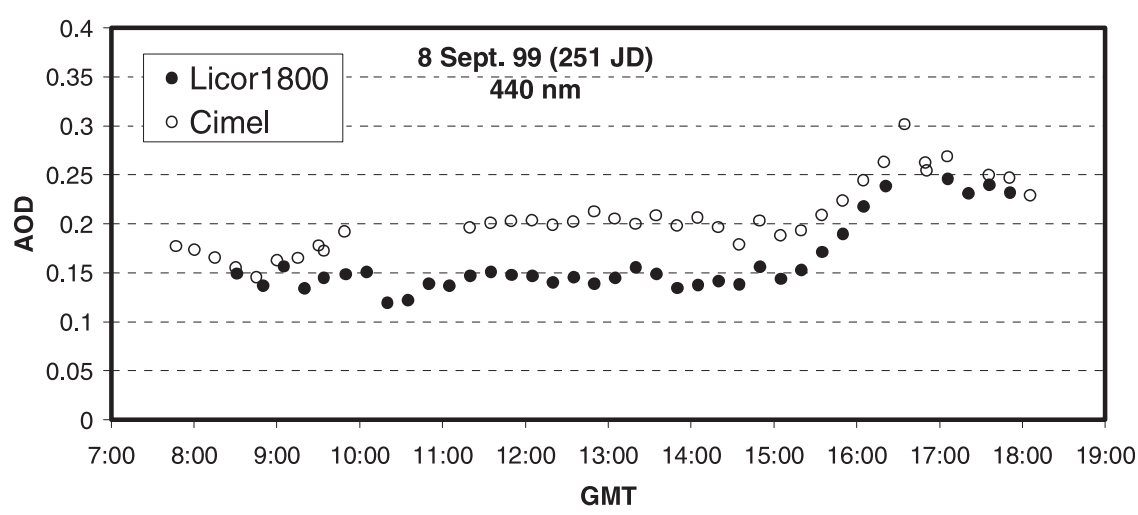

FIG. 2. AOD comparison of Li-Cor and Cimel instruments at the 440-nm filter during the diurnal evolution of 8 Sep 1999. 


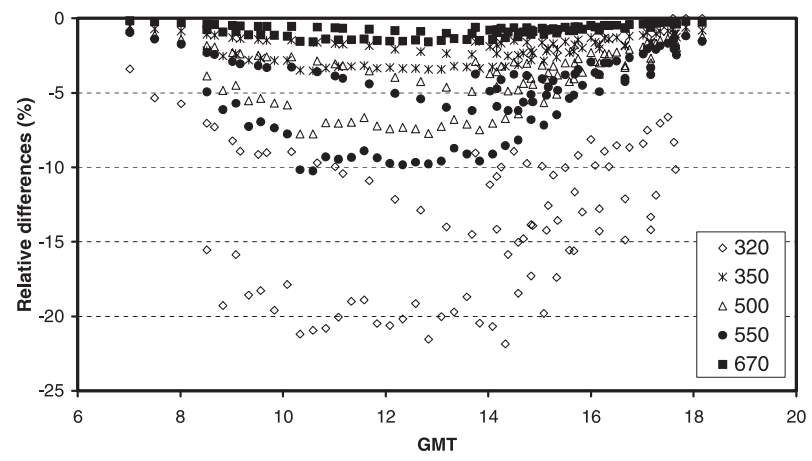

FIG. 3. Temporal evolution of AOD relative difference taken "in situ" calibration factor and calibration "original" for selected wavelengths of $\mathrm{Li}$-Cor spectroradiometer. The figure shows all datasets taken during the first campaign in September 1999.

with absolute differences ranging from 0.01 to 0.06 . The absolute differences for the other wavelength channels decrease slightly at the longer wavelengths, with discrepancies at noon about 0.01 to 0.04 (not shown). However, the relative differences increase with increasing wavelength, reaching values as high as $100 \%$ at noon for filter $870 \mathrm{~nm}$. It is interesting to note the good agreement near the beginning and end of the day, and a significant disagreement at noon; this diurnal variability suggests a calibration error may be present (Cachorro et al. 2008). The problems with the Cimel and the subsequent poor comparison required a revision of the sun photometer and made it unsuitable for comparison with the Li-Cor during this campaign.

Although the results for the Li-Cor 1800 were evaluated with the calibration factor obtained during the intercomparison campaign (in situ), we also evaluated these same data with the precampaign (original) calibration factor, obtained 6 months earlier. In Fig. 3 we illustrate the relative differences between Li-Cor AOD retrieved with the original and with the in situ calibration factors at selected wavelengths, which show clear SZA dependence as predicted by Eq. (3). Taking the data of the entire campaign the relative differences between these two Li-Cor retrievals reach $20 \%$ at $320 \mathrm{~nm}$, with AOD values ranging from 0.2 to 0.5 . At $670 \mathrm{~nm}$ the relative differences are about $1 \%-2 \%$ only, with the highest values at noon, and the AOD values are in the range 0.1 to almost 0.2 . The infrared wavelengths present relative differences as high as $80 \%$, with AOD values varying from 0.08 to 0.13 (not shown).

\section{b. Second campaign: August 2000}

The second campaign was carried out from 7 to 14 August 2000. On three days (9, 10, and 11 August) concurrent measurements can be analyzed, in spite of varying atmospheric conditions. We note the coinci- dence of the campaign with the arrival of a desert dust intrusion over the measurement area. The comparison between the Li-Cor and the Brewer 150 was quite successful as seen in Fig. 4, where we illustrate the comparison separately for each day at $320 \mathrm{~nm}$. We have added the Li-Cor AOD (350 nm) because it is more stable and its values are less scattered (mainly about sunrise and sunset hours) than the 320-nm wavelength.

Even taking into account the different aerosol conditions for each day, good agreement is obtained, with AOD values ranging from 0.2 to 0.6 during 9 (Fig. 4a) and 10 (Fig. 4b) August, and from 0.3 to 1.8 on $11 \mathrm{Au}-$ gust (Fig. 4c). Note that on 11 August there is cloud contamination before $10 \mathrm{~h}$ and after $14 \mathrm{~h}$. AOD in the cloud-free period is around 0.7. Differences between the Brewer and the Li-Cor are especially large around 1500 UTC, as a result of the clouds and the different measurement times for each instrument. For the cloudfree cases, the differences are much lower. Note that AOD values for the Li-Cor instrument were measured using a tracking system manually adjusted by the observer during the entire campaign, and AOD values contaminated by clouds were flagged. The only important differences appear at the beginning and at the end of the day for the reasons mentioned above (again air mass 3 is indicated in the plots of Fig. 4). Note, however, the good behavior of the Li-Cor AOD $(350 \mathrm{~nm})$ with respect to that at $320 \mathrm{~nm}$. The AOD differences are given in Table 3 for the 320-nm wavelength considering only data between 0900 and 1700 UTC on 9 and 10 August; and between 1000 and 1400 UTC on 11 August. The mean absolute difference is 0.034 with a standard deviation STD $=0.030$. The relative differences reached $17.5 \%(\mathrm{STD}=19 \%)$.

Figure 4 also shows AOD (440 nm) obtained with the Cimel sun photometer during 9, 10, and 11 August 2000. The daily pattern confirms the appropriate behavior of Li-Cor and Brewer. The AOD increase on 9 August indicates the arrival of a desert dust event of moderatehigh intensity, which is maintained during the entire day on 10 August. The associated Ångström exponent (from Cimel data) is about 0.3. The next day, 11 August, is characterized by frequent scattered clouds, which are also measured by the Cimel. For this comparison we have used the non-cloud-screened data; that is, AERONET level 1.0.

A more detailed comparison between the Li-Cor and Cimel is shown in Fig. 5, where each day and channel is shown separately. The mean absolute AOD differences (Table 3) are within the Cimel uncertainty of 0.02 except for $870 \mathrm{~nm}$. On 9 and 10 August (Figs. 5a,b), the atmospheric conditions are stable although AOD values are high, between 0.3 and 0.5 for the four channels. Also 

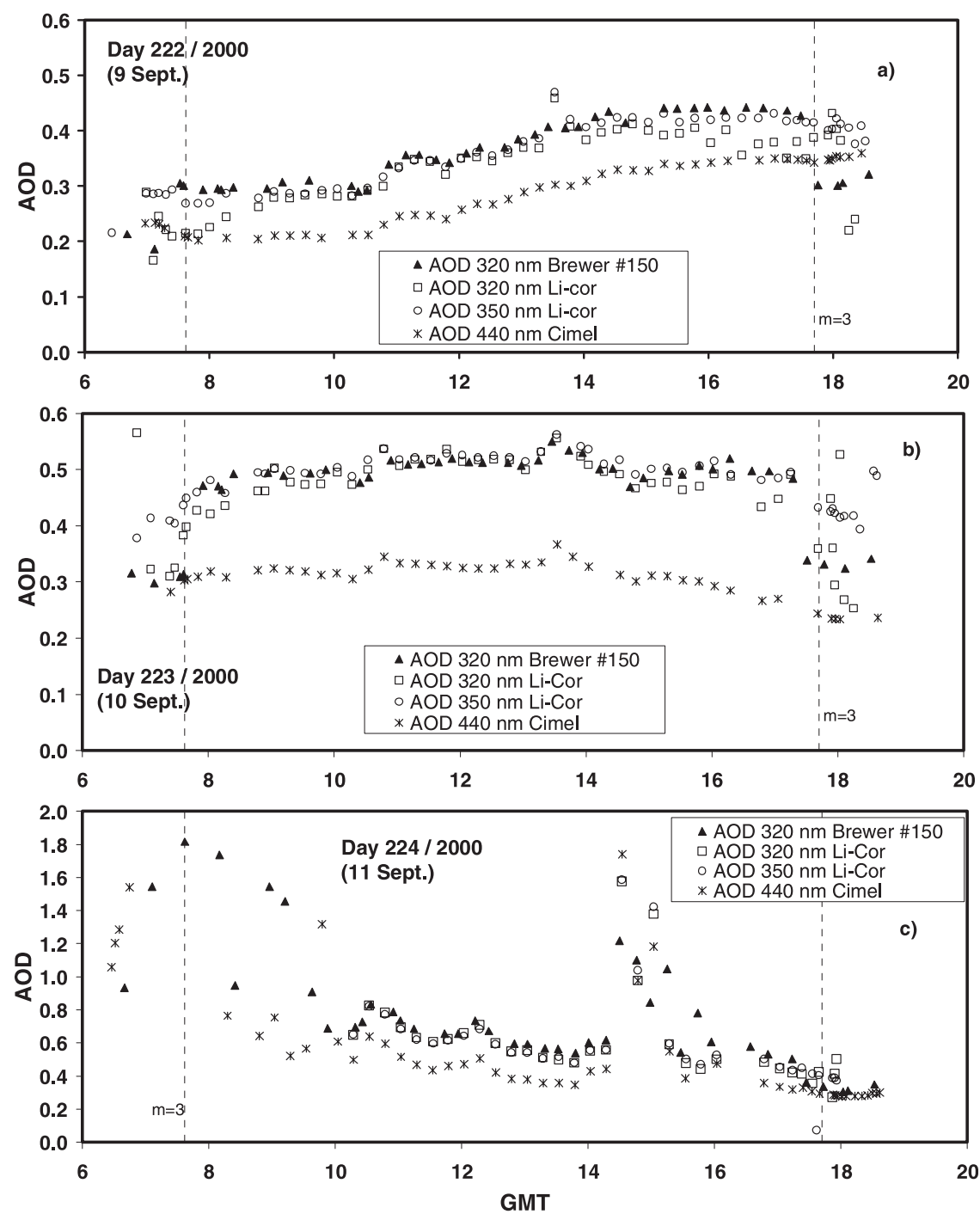

FIG. 4. AOD comparison of Li-Cor and Brewer instruments at $320 \mathrm{~nm}$ during 9, 10, and 11 Aug 2000. The Li-Cor AOD at $350 \mathrm{~nm}$ and the Cimel AOD (440 nm) are also shown. Vertical dotted lines indicate air mass 3 .

we note the smaller differences at sunrise and sunset and the higher differences at noon, which according to Eq. (3) suggests some small calibration error. However, since the differences stay within the estimated uncertainty of the
Cimel ( $\sim 0.02)$, no further corrections were applied. On 11 August (Fig. 5c) the cloudiness makes the comparison very difficult, although the differences are still below 0.02 in most cases for the period of 1000-1400 UTC.

TABLE 3. Absolute and relative differences with its standard deviation for the comparison between Li-Cor, and Brewer 150 for AOD (320 nm); and between Li-Cor and Cimel 114 at 440-, 670-, 870-, and 1020-nm AOD channels. Data considered for the statistics are from 0900 to 1700 UTC 9 and 10 Aug; and from 1000 to 1400 UTC 11 Aug.

\begin{tabular}{|c|c|c|c|c|c|}
\hline AOD comparison 2000 & $\begin{array}{l}\text { Li-Cor-Brew } 150 \\
\quad(320 \mathrm{~nm})\end{array}$ & $\begin{array}{l}\text { Li-Cor-Cimel } \\
\quad(440 \mathrm{~nm})\end{array}$ & $\begin{array}{l}\text { Li-Cor-Cimel } \\
\quad(670 \mathrm{~nm})\end{array}$ & $\begin{array}{l}\text { Li-Cor-Cimel } \\
\quad(870 \mathrm{~nm})\end{array}$ & $\begin{array}{l}\text { Li-Cor-Cimel } \\
\quad(1020 \mathrm{~nm})\end{array}$ \\
\hline Mean absolute difference & -0.034 & 0.013 & 0.016 & 0.024 & 0.011 \\
\hline STD & 0.03 & 0.009 & 0.008 & 0.012 & 0.008 \\
\hline Mean relative differences (\%) & -17.5 & 8.2 & 7.5 & 7.2 & 6.8 \\
\hline STD $(\%)$ & 19 & 6.7 & 5.8 & 4.3 & 4.7 \\
\hline
\end{tabular}



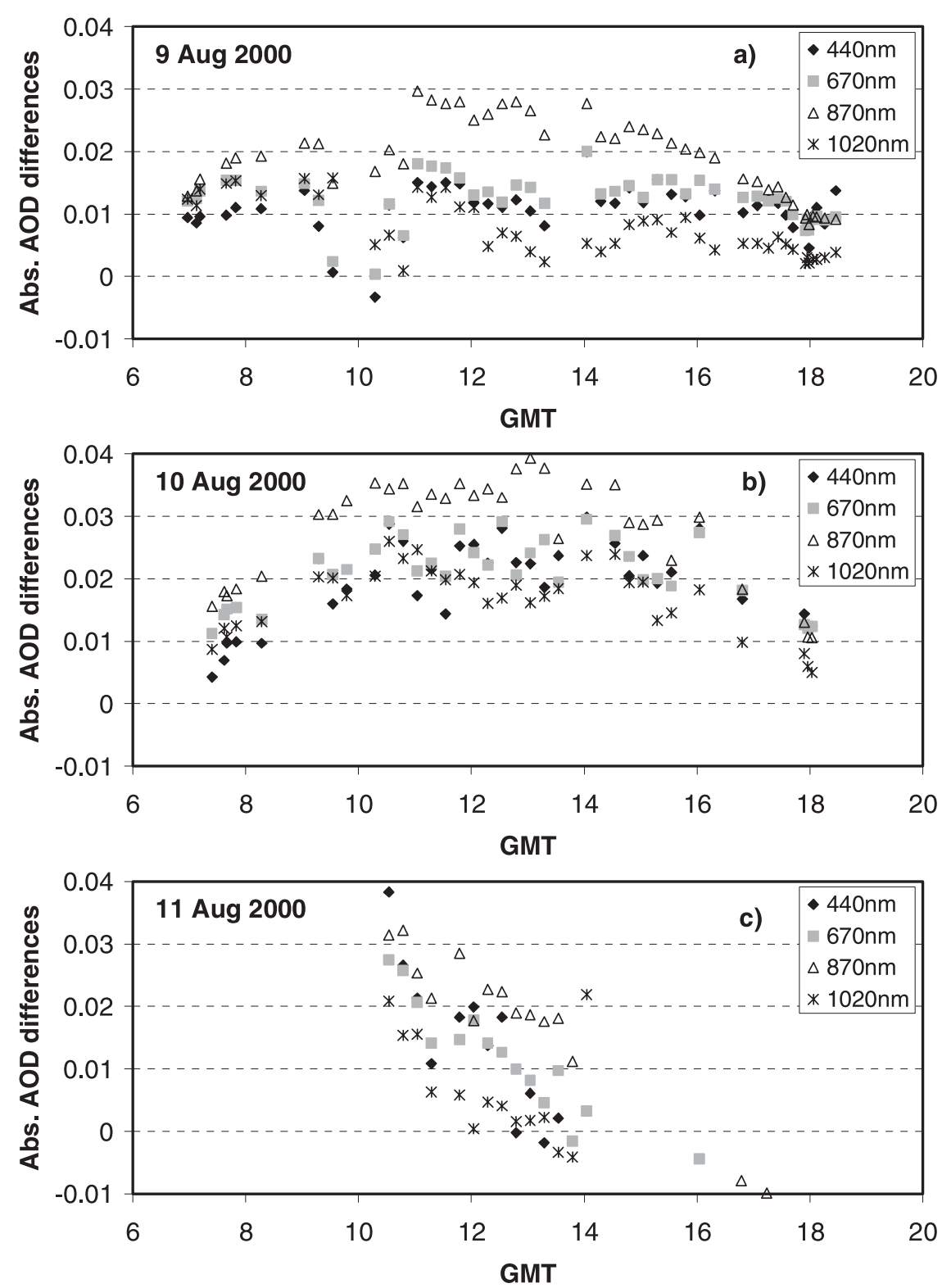

FIG. 5. Absolute AOD differences between the Li-Cor and the Cimel for the visible and infrared channels, calculated as AOD (Li-Cor) - AOD (Cimel).

The comparison between the Li-Cor and the Cimel at the four wavelength pairs clearly shows the level of agreement that can be obtained under normal operations (Table 3). Mean absolute difference values range from 0.011 to 0.024 depending on the wavelength, with relative mean differences of about $6 \%-8 \%$. Mean differences are considerably lower than point-to-point differences, reflecting the smoothing in the comparison results when a certain amount of data is averaged.

The agreement between instruments is also shown in Fig. 6 by means of the AOD spectrum. The Li-Cor AOD spectrum overlaps with the Brewer AOD (306-320 nm) and the four Cimel channels. The Ångström fit, calculated with the Cimel data in the range $440-870 \mathrm{~nm}$, is also shown. The differences in the UV are within the estimated uncertainties ( 0.08 for Brewer and Li-Cor). In the visible, the agreement of Li-Cor and Cimel is excellent, except in the spectral regions of strong absorption by gases. The choice of the Cimel wavelength channels is obviously appropriate for AOD monitoring. In the infrared, the discrepancies Cimel-Li-Cor are larger, probably caused by temperature effects in the Li-Cor. The selected measurement, near noon (1115 UTC on 10 August), reflects the maximum errors 


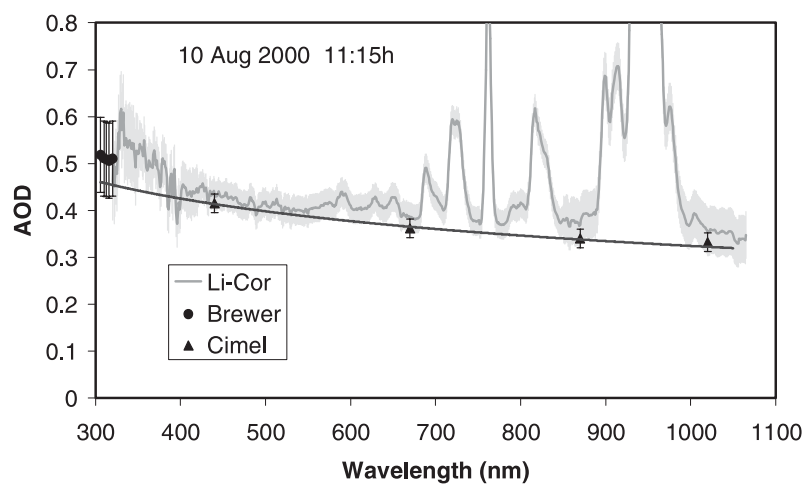

FIG. 6. Wavelength dependence of the AOD obtained with the Brewer, Cimel, and Li-Cor. For the Li-Cor, the absorption bands (water vapor, oxygen) have not been removed. The Angström fit $(\mathrm{AE}=0.30)$ has been calculated with the Cimel data over the spectral range 440-870 $\mathrm{nm}$. Error bars are indicated for the Cimel, Brewer, and Li-Cor (gray bands).

caused by calibration (see Fig. 5). The strong AOD increase given by the Li-Cor is seen from 450 to $350 \mathrm{~nm}$, which apparently does not agree with the lower AOD by the Brewer $(320 \mathrm{~nm})$. The Li-Cor AOD decreases, however, from 350 to $320 \mathrm{~nm}$, but close to $320 \mathrm{~nm}$ it is evidently unstable.

\section{c. Third Campaign: October 2001}

The third intercomparison campaign was carried out from 1 to 8 October 2001, under clear and cloudy skies and with scattered showers during these days. In general atmospheric conditions were poor. A different AERONET Cimel instrument (number 45) was deployed at this time. Two different AOD retrievals from the Cimel will be shown: 1) the AERONET level 2 data, and 2) the AOD determined by the KCICLO method.

As a result of the cloudy skies, we only show the comparison between the Li-Cor and the Cimel on 4 October. The results are depicted in Fig. 7a for 440 and $670 \mathrm{~nm}$. The observed differences are in part caused by different measurement schedules for the two instruments and the large variability during the afternoon as a result of thin cirrus clouds. Similar results are given by the other two wavelength channels (not shown). The most relevant factor in these results is that the AOD differences are within 0.02 between Li-Cor and Cimel, even though the $\mathrm{Li}$-Cor was calibrated three months before the campaign.

However, the most surprising result was the AOD retrieved with the Brewer (Fig. 7b) at 320-nm wavelength. The Brewer AOD values are approximately constant during the day, about 0.1 , while those of Li-Cor are about 0.25 . These large discrepancies are repeated during the other days of the campaign (not shown).
Taking into account that the Brewer data are also lower than those of the Cimel and Li-Cor at $440-\mathrm{nm}$ wavelength, we must assume that the Brewer had a calibration problem. We could not find a probable cause for this large difference when comparing these results to those of previous campaigns. Inspection of the ozone content and the global ultraviolet spectral irradiance data recorded during this campaign did not reveal any instrument malfunction.

We have observed these same large discrepancies in AOD during the Veleta campaign carried out over a wide area of the Sierra Nevada, Granada, in July 2002 (Alados-Arboledas et al. 2004). In this campaign an AOD intercomparison between various Li-Cor and Cimel sun photometers was carried out (Estelles et al. 2006) with very good results, but no comparison with Brewer AOD was presented because of the observed large discrepancies. It is obvious that the calibration constants for the Brewer seem not to be adequate for AOD retrieval during these two periods (summer 2001 and summer 2002). These examples show the large uncertainties linked with the retrieval of AOD with the Brewer spectroradiometer and the necessity of evaluating a large dataset in order to detect and fix the problem linked with calibration constants and with the retrieval itself.

\section{Conclusions}

This paper presents a realistic comparison between three different instruments for AOD retrieval during three short and intensive campaigns carried out in 1999, 2000, and 2001. In the analyzed days there were different atmospheric turbidity conditions, including a dust event. The results of the comparison at selected wavelengths, from the UV to the near-infrared, show the difficulties to get reliable AOD data. Operational systems such as the Brewer, or other frequently used spectroradiometers, such as the Li-Cor, do not satisfy the absolute limit of 0.02 for the estimated uncertainty in AOD, as recommended by the WMO/GAW. The Cimel sun photometer data are close to this uncertainty in operational conditions and give more reliable results.

The relative and absolute differences of the mean values cover a wide range, from low values of $1 \%-2 \%$ up to very high values of $20 \%-30 \%$ (more than $100 \%$ in cases of point-by-point differences). Although the comparison shows a reasonable agreement and the obtained values are within the evaluated instrumental uncertainties in most cases, data from the Brewer often show poor results, which is likely caused by the calibration constants used for AOD retrieval. The on-site 

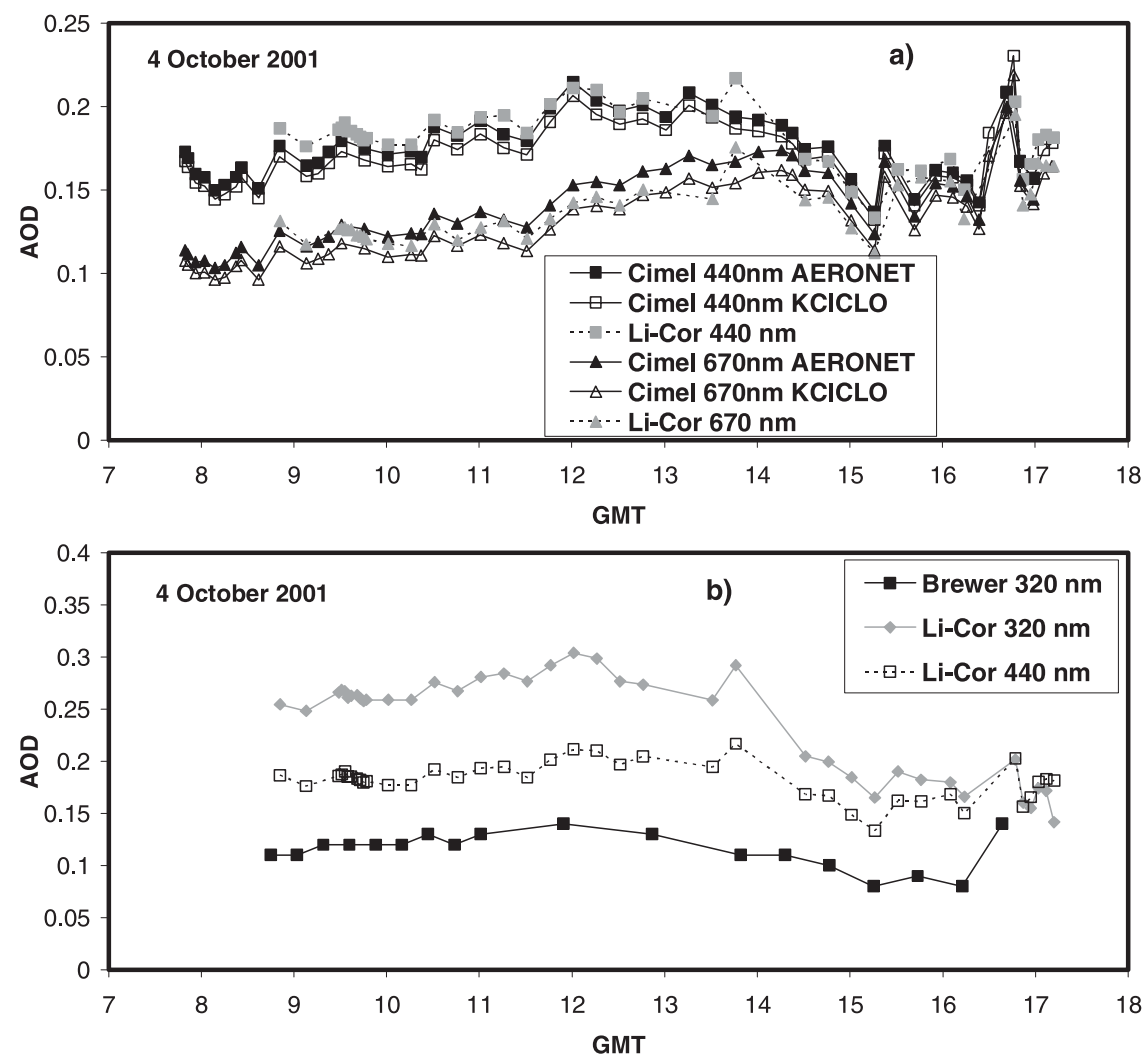

FIG. 7. (a) AOD comparison of Li-Cor and Cimel on 4 Oct 2001, using the AERONET level 2 and the KCICLO calibration factors. Channels 440 and $670 \mathrm{~nm}$ are shown. (b) AOD comparison of Li-Cor at 440 and $320 \mathrm{~nm}$ and Brewer at $320 \mathrm{~nm}$ on 4 Oct 2001.

Langley procedure in the UV region used for Brewer absolute calibration might be difficult to apply in many sites, given the difficulties encountered in a sunny site such as El Arenosillo.

The comparison between the Cimel and Li-Cor strongly depends on a good calibration of the latter instrument. The comparison with the reliable Cimel database supports the AOD retrieved with the $\mathrm{Li}$-Cor. Absolute differences between these instruments in the spectral range $440-1020 \mathrm{~nm}$ are mostly within 0.02 . In general Brewer-Li-Cor differences are larger and show greater scatter, especially at large solar zenith angles. Brewer AOD retrieval needs further development related with the calibration process and the measurement procedure to monitor AOD in operational conditions.

Acknowledgments. This work has been supported by a grant from the Spanish Ministerio de Educación y Ciencia by means of Project CGL2005-05693-C03/CLI and VA001C05. We also thank the program Grupos de Excelencia de Cyl (GR220) of the Junta de Castilla y León. We thank Alberto Redondas of Izaña Observatory for providing Brewer157 data, and all participating people in the First Iberian UV-VIS Instruments Intercomparison campaign, especially to J.A. MartinezLozano and P. Utrillas from the University of Valencia. One of us (NL) was supported by the U.S. Department of Energy under Contract DE-AC06-76RLO 1830. Pacific Northwest National Laboratory is operated for the U.S. DOE by Battelle Memorial Institute.

\section{REFERENCES}

Ahern, F., R. Gautier, P. Teillet, J. Sirois, G. Fedosejevs, and D. Lorente, 1991: Investigation of continental aerosols with high-spectral-resolution solar extinction measurements. Appl. Opt., 30, 5276-5287.

Alados-Arboledas, L., and Coauthors, 2004: VELETA field campaign-A general overview. Opt. Pura Apl., 37, 3271-3276.

Arola, A., and T. Koskela, 2004: On the sources of bias in aerosol optical depth retrieval in the UV range. J. Geophys. Res., 109, D08209, doi:10.1029/2003JD004375.

Cachorro, V., P. Durán, A. de Frutos, and R. Vergaz, 2000: Measurements of the atmospheric turbidity of the northcenter continental area in Spain: Spectral aerosol optical thickness and Angström turbidity parameters. J. Aerosol Sci., 31, 687-702.

— C. Toledano, A. de Frutos, J. Vilaplana, P. Romero, and E. Cuevas, 2003: Retrieval of aerosol optical depth (AOD) by 
the Brewer instrument: Detection and correction of calibration problem by a new method. Proc. Eighth Biennial Brewer Users Working Group Meeting, Huelva, Spain, 22-24.

—- P. Romero, C. Toledano, E. Cuevas, and A. de Frutos, 2004: The fictitious diurnal cycle of aerosol optical depth: A new approach for "in situ" calibration and correction of AOD data series. Geophys. Res. Lett., 31, L12106, doi:10.1029/ 2004GL019651.

—, C. Toledano, A. Berjón, A. M. de Frutos, B. Torres, M. Sorribas, and N. S. Laulainen, 2008: An "in situ" calibration correction procedure (KCICLO) based on AOD diurnal cycle: Application to AERONET-El Arenosillo (Spain) AOD data series. J. Geophys. Res., 113, D12205, doi:10.1029/ 2007JD009673.

Carlund, T., T. Landelius, and W. Josefsson, 2003: Comparison and uncertainty of aerosol optical depth estimates derived from spectral and broadband measurements. J. Appl. Meteor., 42, $1598-1610$.

Carvalho, F., and D. Henriques, 2000: Use of Brewer ozone spectrophotometer for aerosol optical depth measurements on ultraviolet region. Adv. Space Res., 25, 997-1006.

Cheymol, A., and H. D. Backer, 2003: Retrieval of the aerosol optical depth in the UV-B at Uccle from Brewer ozone measurements over a long time period 1984-2002. J. Geophys. Res., 108, 4800, doi:10.1029/2003JD003758.

-, H. Backer, W. Josefsson, and R. Stübi, 2006: Comparison and validation of the aerosol optical depth obtained with the Langley plot method in the UV-B from Brewer Ozone Spectrometer measurements. J. Geophys. Res., 111, D16202, doi:10.1029/2006JD007131.

Chu, D., Y. Kaufman, C. Ichoku, L. Remer, D. Tanré, and B. Holben, 2002: Validation of MODIS aerosol optical depth retrieval over land. Geophys. Res. Lett., 29, 8007, doi:10.1029/ 2001 GL013205.

Cuomo, V., F. Esposito, G. Pavese, and C. Serio, 1993: Determining Angstrom turbidity coefficients. An analysis with a wide range grating spectrometer. Aerosol Sci. Technol., 18, 59-69.

Esposito, F., C. Serio, and H. Horvath, 1996: Vertical and horizontal aerosol spectral extinction at a rural location in southern Italy. J. Geophys. Res., 101D, 19 285-19 292.

Estelles, V., and Coauthors, 2006: Intercomparison of spectroradiometers and sun photometers for the determination of the aerosol optical depth during the VELETA2002 field campaign. J. Geophys. Res., 111, D15214, doi:10.1029/2005JD006047.

Gröbner, J., and C. Meleti, 2004: Aerosol optical depth in the UVB and visible from Brewer spectrophotometer direct irradiance measurements: 1991 to 2002. J. Geophys. Res., 109, D09202, doi:10.1029/2003JD004409.

, R. Vergaz, V. Cachorro, D. Henriques, K. Lamb, A. Redondas, J. Vilaplana, and D. Rembges, 2001: Intercomparison of aerosol optical depth measurements in the UVB using Brewer spectrophotometers and a Li-Cor spectrophotometer. Geophys. Res. Lett., 28, 1691-1694.

Gueymard, C., 2004: The sun's total and spectral irradiance for solar energy applications and solar radiation models. Sol. Energy, 76, 423-453.

Holben, B., and Coauthors, 1998: AERONET-A federated instrument network and data archive for aerosol characterization. Remote Sens. Environ., 66, 1-16.

, and Coauthors, 2001: An emerging ground-based aerosol climatology: Aerosol Optical Depth from AERONET. J. Geophys. Res., 106D, 12 067-12 097.
Ichoku, C., L. Remer, and T. Eck, 2005: Quantitative evaluation and intercomparison of morning and afternoon Moderate Resolution Imaging Spectrometer (MODIS) aerosol measurements from Terra and Aqua. J. Geophys. Res., 110, D10S03, doi:10.1029/2004JD004987.

Jaroslawsky, J., J. Krzyscin, S. Puchalsky, and P. Sobolewski, 2003: On the optical thickness in the UV range: Analysis of the ground-based data taken at Belsk, Poland. J. Geophys. Res., 108, 4722, doi:10.1029/2003JD003571.

Kasten, F., and A. Young, 1989: Revised optical air mass tables and approximation formula. Appl. Opt., 28, 4735-4738.

Kazadzis, S., A. Bais, N. Kouremeti, E. Garasopoulos, K. Garane, M. Blumthaler, B. Schallhart, and A. Cede, 2005: Direct spectral measurements with a Brewer spectroradiometer: absolute calibration and aerosol optical depth retrieval. Appl. Opt., 44, 1681-1690.

— measurements at Thessaloniki, Greece. Atmos. Chem. Phys., 7, 2091-2107.

Kerr, J. B., 2002: New methodology for deriving total ozone and other atmospheric variables from Brewer spectrophotometer direct sun spectra. J. Geophys. Res., 107, D234731, doi:10.1029/ 2001JD001227.

—_, and J. M. Davis, 2007: New methodology applied to deriving total ozone and other atmospheric variables from global irradiance spectra. J. Geophys. Res., 112, D21301, doi:10.1029/ 2007JD008708.

_ C. McRoy, and R. Olafson, 1981: Measurements of ozone with Brewer ozone spectrophotometer. Proc. Quadrennial Int. Ozone Symp., Troms $\varnothing$, Norway, International Association for Meteorology and Atmospheric Sciences, 74-79.

Kirchhoff, V., A. Silva, C. Costa, N. P. Lem, H. Pavao, and F. Zaratti, 2001: UV-B optical thickness observations of the atmosphere. J. Geophys. Res., 106, 2963-2973.

Labajo, A., E. Cuevas, and B. de la Morena, 2004: First Iberian UV-VIS instruments intercomparison. Final Rep., Centro de Publicaciones, Ministerio de Medio Ambiente. Dirección General del Instituto de Meteorología, 114 pp.

Li-Cor, 1989: Li-1800 Portable spectroradiometer instruction manual. LI-COR Inc., 149 pp.

Marenco, F., A. di Sarra, and J. de Luisi, 2002: Methodology for determining aerosol optical depth from Brewer 300-320 nm measurements. Appl. Opt., 41, 1805-1814.

Martinez-Lozano, J., and Coauthors, 2003: Intercomparison of spectroradiometers for global and direct irradiance in the visible range. J. Atmos. Oceanic Technol., 20, 997-1010.

Masuda, K., H. Ishimoto, and T. Takashima, 2002: Dependence of the aerosol optical thickness retrieval from the space on measurements errors and model assumption. Int. J. Remote Sens., 23, 3835-3846.

Reagan, J. A., L. W. Thomason, B. M. Herman, and J. M. Palmer, 1986: Assessment of atmospheric limitations on the determination of the solar spectral constant from ground-based spectroradiometer measurements. IEEE Trans. Geosci. Remote Sens., GE-24, 258-266.

Redondas, A., J. Gröbner, J. Díaz, F. Expósito, C. Torres, V. Carreño, and J. Vilaplana, 2004: Intercomparison of solar UV measurements: Spectrals and broadband. First Iberian UV-VIS Instruments Intercomparison. Final Rep., L. Labajo, E. Cuevas, and B. de la Morena, Eds., Centro de Publicaciones, Ministerio de Medio Ambiente, Dirección General del Instituto de Meteorología, 41-64. 
Slusser, J., J. Gibson, D. Bigelow, D. Kolinski, P. Disterhoft, K. Lantz, and A. Beaubien, 2000: Langley method of calibrating UV filter radiometers. J. Geophys. Res., 105D, 48414849.

Toledano, C., V. E. Cachorro, M. Sorribas, A. Berjón, B. A. de la Morena, A. M. de Frutos, and P. Gouloub, 2007: Aerosol optical depth and Angström exponent climatology at El Arenosillo AERONET site (Huelva, Spain). Quart. J. Roy. Meteor. Soc., 133, doi:10.1002/qj.54.
Vergaz, R., V. Cachorro, A. de Frutos, D. Henriques, J. Vilaplana, and B. de la Morena, 2005: Columnar characteristics of aerosols in the maritime area of the Cádiz Gulf (Spain). Int. J. Climatol., 25, 1793-1804.

Wehrli, C., 2000: PFR Precision Filter Radiometer, Version 3.0. World Radiation Center, Observatorium Davos.

WMO/GAW, 2003: Aerosol measurements procedures guidelines and recommendations. Tech. Rep. 153, World Meteorological Organization, $39 \mathrm{pp}$ 
Copyright of Journal of Atmospheric \& Oceanic Technology is the property of American Meteorological Society and its content may not be copied or emailed to multiple sites or posted to a listserv without the copyright holder's express written permission. However, users may print. download, or email articles for individual use. 